\title{
An Integrative Way for Studying Neural Basis of Basic Emotions With fMRI
}

\author{
Simeng Gu ${ }^{1,2}$, Fushun Wang ${ }^{1,3,4 *}$, Caiyun Cao ${ }^{3}$, Erxi Wu ${ }^{4,5,6,7}$, Yi-Yuan Tang ${ }^{8}$ and \\ Jason H. Huang $4,5,6,7$
}

${ }^{1}$ Institute of Brain and Psychological Science, Sichuan Normal University, Chengdu, China, ${ }^{2}$ Department of Psychology, Jiangsu University, Zhenjiang, China, ${ }^{3}$ Department of Pharmacology, Nanjing University of Chinese Medicine, Nanjing, China, ${ }^{4}$ Department of Neurosurgery, Baylor Scott \& White Health, Temple, TX, United States, ${ }^{5}$ Department of Surgery, Texas A\&M University College of Medicine, Temple, TX, United States, ${ }^{6}$ Department of Pharmaceutical Sciences, Texas A\&M University College of Pharmacy, College Station, TX, United States, ${ }^{7}$ LIVESTRONG Cancer Institutes, Dell Medical School, The University of Texas at Austin, Austin, TX, United States, ${ }^{8}$ Department of Psychological Sciences, Texas Tech University, Lubbock, TX, United States

OPEN ACCESS

Edited by:

Wenbin Guo,

Central South University, China

Reviewed by:

Fu Wenqing,

Soochow University, China Chaoxiong Ye,

University of Jyväskylä, Finland

*Correspondence:

Fushun Wang

13814541138@163.com

Specialty section:

This article was submitted to Brain Imaging Methods,

a section of the journal

Frontiers in Neuroscience

Received: 04 December 2018

Accepted: 31 May 2019

Published: 19 June 2019

Citation:

Gu S, Wang F, Cao C, Wu E, Tang $Y$ - $Y$ and Huang JH (2019) An Integrative Way for Studying Neural Basis of Basic Emotions With fMRI.

Front. Neurosci. 13:628.

doi: 10.3389/fnins.2019.00628
How emotions are represented in the nervous system is a crucial unsolved problem in the affective neuroscience. Many studies are striving to find the localization of basic emotions in the brain but failed. Thus, many psychologists suspect the specific neural loci for basic emotions, but instead, some proposed that there are specific neural structures for the core affects, such as arousal and hedonic value. The reason for this widespread difference might be that basic emotions used previously can be further divided into more "basic" emotions. Here we review brain imaging data and neuropsychological data, and try to address this question with an integrative model. In this model, we argue that basic emotions are not contrary to the dimensional studies of emotions (core affects). We propose that basic emotion should locate on the axis in the dimensions of emotion, and only represent one typical core affect (arousal or valence). Therefore, we propose four basic emotions: joy-on positive axis of hedonic dimension, sadness-on negative axis of hedonic dimension, fear, and anger-on the top of vertical dimensions. This new model about basic emotions and construction model of emotions is promising to improve and reformulate neurobiological models of basic emotions.

Keywords: basic emotions, core affects, monoamine, dimensional studies, fMRI

\section{INTRODUCTION}

Emotion is a kind of mental state that occurs at almost all times across life. Despite the critical importance of emotions in our lives, there is currently no scientific consensus on a definition about what emotion is (Gu et al., 2015). Controversy still abounds over the definition of emotions; the number of emotions that exit. Fehr and Russell (1984) wrote that "everyone knows what an emotions is, until asked to give a definition. Then, it seems no one knows" (Fehr and Russell, 1984). Emotions are internal states that are evoked by comparison between the internal bodily needs and the available external materials, and are characterized by induced physiological changes, behavioral 
and cognitive changes (Sroufe, 1996; Wang, 2018). The JamesLange Theory of Emotion suggested that the perception of these bodily changes is what is called an emotion. However, emotions themselves are neither physiological changes nor behavioral changes, because emotions can be separated from behavioral changes, for example, you can hold back fighting behaviors even though you are angry (Damasio and Carvalho, 2013; Wang, 2018). Anyway, emotions can only be consciously known by human beings, and only human beings can consciously regulate their emotions (Etkin et al., 2015, 2016; Hay et al., 2015; Milyavsky et al., 2018); animals cannot hold back the emotion related physiological changes or behaviors. Therefore, it is hard to say emotions are only neuromodulators separately or inseparately with behaviors. However, emotions can only be studied with these external expressions, such as physiological or behavioral changes, especially facial expressions, because we still cannot study animal emotions directly as we have no access to an organism's subjective experience (Papini et al., 2018). Darwin was the first to use facial expressions in emotional studies, such as fear, anger, joy, or sadness. Later, behaviorists tried to study behaviors using emotion induced physiological changes, such as saliva in Palov's dog, and other behavior changes by Skinner's pigeon at a reward or punishment. All these studies did not answer one critical question about emotions: How many kinds of emotions humans have. In contrast, the question is getting more emergent.

During the past decades, basic emotion theory has been very influential in the field of affective studies (Saarimaki et al., 2016; Celeghin et al., 2017; Williams, 2017; Hutto et al., 2018; Song and Hakoda, 2018; Vetter et al., 2018; Wang et al., 2018), which proposed that all human emotions are composed of limited number of basic emotions (e.g., fear, anger, joy, sadness), which are considered to be more elementary than others. These emotions are called basic emotions, for they are biologically and psychologically "basic". These basic emotions are related to our basically biological needs (Lindquist and Barrett, 2012; Colombetti, 2014; An et al., 2017), and each emotion has its own dedicated neural circuitry that is architecturally distinct (Ekman, 1992; Russell, 2006; Barrett and Russell, 2015; Scarantino, 2015). For example, Izard argued that the basic emotions are preserved because their biological and social functions are essential in evolution and adaption, and he suggested that basic emotions have innate neural substrates and universal behavioral phenotypes (Damasio and Carvalho, 2013). Even though many psychologists accepted the theory of basic emotion, there is no consensus as to the exact number of basic emotions. For example, Ekman proposed six basic emotions: happiness, anger, sadness, fear, disgust, and surprise, while Izard proposed seven basic emotions: fear, anger, happiness, sadness, disgust, interest, and contempt. In addition, several recent papers, depending on facial expression studies and neural mechanism studies, suggest four basic emotions: fear, anger, joy, and sadness (Jack et al., 2014; Gu et al., 2016, 2018; Zheng et al., 2016). Many other psychologists also proposed many other basic emotions, as reviewed in a paper by Ortony in Emotion Review (Clore and Ortony, 2013), shown in the Table 1.

The basic emotion theory proposed that each emotion has its own dedicated neural circuitry that is architecturally distinct.
TABLE 1 | Basic emotions.

\begin{tabular}{|c|c|}
\hline Theorist & Basic emotions \\
\hline Arnold & $\begin{array}{l}\text { Fear, anger, desire, despair, hope, love, } \\
\text { courage, sadness, aversion, hate, dejection }\end{array}$ \\
\hline Plutchik & $\begin{array}{l}\text { Fear, anger, joy, sadness, anticipation, disgust, } \\
\text { surprise, acceptance }\end{array}$ \\
\hline Ekman, Friesen, and Ellsworth & Fear, anger, joy, sadness, disgust, surprise \\
\hline Frijda & Joy, surprise, wonder, sorrow, interest, desire \\
\hline McDougall & $\begin{array}{l}\text { Fear, anger, disgust, wonder, elation, } \\
\text { subjection, tender-emotion }\end{array}$ \\
\hline Izard & $\begin{array}{l}\text { Fear, anger, joy, contempt, disgust, distress, } \\
\text { shame, guilt, interest, surprise }\end{array}$ \\
\hline Tomkins & $\begin{array}{l}\text { Fear, anger, joy, interest, contempt, disgust, } \\
\text { distress, shame, surprise }\end{array}$ \\
\hline Oatley and Johnson-Laird & Anger, happiness, sadness, anxiety, disgust \\
\hline Gray & Rage and terror, anxiety, joy \\
\hline Fushun Wang, and Jack RE & Fear, anger, joy, sadness \\
\hline
\end{tabular}

For example, fear is a kind of emotion that produce subjective feelings through separate neural pathways of the central nervous system, or peripheral nervous systems (Cowen and Keltner, 2018). Therefore, studying the neural basis might be the best way to differentiate the basic emotions and probe into the number of basic emotions. However, many fMRI studies have met some troubles in differentiating the basic emotions (such as fear, anger, joy, sad, and disgust) with distinct universal signals, physiology, especially the localization of the central nervous system (Lindquist and Barrett, 2012; Lindquist et al., 2012), which has led to even more controversies about the basic emotions (Posner et al., 2005; Scarantino and Griffiths, 2011; Scarantino, 2015; Hutto et al., 2018). For example, even though neuroimaging studies found some evidence for basic emotions [such as amygdala for fear (Ohman, 2005), insula for disgust (Wicker et al., 2003), anterior cingulate cortex for sadness, orbitofrontal cortex for anger (Murphy et al., 2003)], these neuroimaging data are not consistent with specific one-toone correspondence between fMRI localization of anger, sadness, fear, disgust, etc (Lindquist et al., 2012; Clark-Polner et al., 2017). These neuroimaging data have challenged the basic emotion theory (Hamann, 2012; Scarantino, 2012; Barrett and Satpute, 2013; Cowen and Keltner, 2018), leading many psychologists to suspect (if not give up) the basic emotion theory (Scarantino and Griffiths, 2011; Colombetti, 2014; Scarantino, 2015; Cowen and Keltner, 2018; Hutto et al., 2018). Actually, the reason for the complication might be due to the fact that the basic emotions used in these experiments are not "basic" enough, as they can be further divided into even more "basic" emotions; or the "basic emotions" used in previous reports did not in fact represent the most psychologically primitive levels of emotion (Lindquist and Barrett, 2012). Indeed, Colombetti (2014, p. 38) suggested that the six basic emotions in Ekman's study were not chosen "on the basis of a clear rationale" (Colombetti, 2014). Indeed, they chose the six emotions because they could not obtain enough suitable sample photographs (Colmbetti, 2014; Hutto et al., 2018). Here we probe into the question whether humans have four basic emotions, based on fMRI data. 


\section{FMRI DATA ON BASIC EMOTIONS}

Recent studies with fMRI offer a good opportunity to study the underlying brain mechanisms for basic emotions, and these neuroimaging studies found some specific loci in the brain work for basic emotions, while other regions are generally involved in emotion perception, valuation, or regulation (Phan et al., 2002; Lindquist et al., 2012, 2013b).

\section{Happiness}

Happiness is one of the human resources that an individual can pursuit in his life. The psychological study of happiness defined two different conceptions of happiness: hedonic happiness and eudaimonic happiness (Berridge and Kringelbach, 2011). Hedonic happiness is what we feel during the experience of intense physical or psychological pleasure, while eudaimonic happiness is what we feel when we reach our personal goals or when we have expressed our potential, our abilities, or to be who we really are (Berridge and Kringelbach, 2011). Indeed, imagination of happy events from both kinds, compared to the imagination of neutral events, activates the ventral prefrontal cortex (including orbitofrontal cortex) (Kringelbach, 2005). In a functional magnetic resonance imaging (fMRI) experiment, Rolls et al. (2008) found that activations in the ventral prefrontal cortex, the cingulate cortex, and the ventral striatum were associated with the positive hedonic state, depending on the correlations between the ratings of the participants on pleasantness with the blood-oxygen-level dependent (BOLD) signal. Later on, many studies provide evidence for the primordial role played by these areas in hedonic valuation (Rolls et al., 2008; Grabenhorst and Rolls, 2011). There is almost no controversy regarding the involvement of the ventromedial prefrontal cortex in the subjective happiness and hedonic value (Abler et al., 2005). However, it is still uncertain whether these frontal regions can cause pleasure, and data from lobotomised patients do not indicate a total loss of pleasure; on the contrary, some patients showed euphoria, impulsiveness and general disinhibition. Similarly, Beer et al. (2003) demonstrated the performance of good humor and self-satisfaction in patients with orbitofrontal damage. These data suggest that the OFC could be more important in transforming pleasure stimuli into their cognitive representations (Burke et al., 2007, 2008, 2009; Takahashi et al., 2009). In addition, there are some reports about the differences between hedonic and eudaimonic happiness; where hedonic pleasure was positively correlated with functional connectivity of bilateral ventral medial prefrontal cortex, while eudaimonic pleasure was shown to be related to bilateral precuneus (Luo et al., 2017). In addition, it is found that ventral striatum activation during eudaimonic decisions predicted longitudinal declines in depressive symptoms, whereas, ventral striatum activation to hedonic decisions were related to longitudinal increases in depressive symptoms (Telzer et al., 2014).

The mesolimbic dopaminergic system has been considered to be able to cause pleasure (Yokel and Wise, 1975; Wise and Rompre, 1989; Wise, 2004, 2006, 2008, 2013). Even though it is hard to visualize the ventral tegmental area (VTA) with fMRI, due to its lacking clear anatomical borders (Trutti et al., 2019), there are some fMRI studies that report the activities of VTA in the reward and happiness (Krebs et al., 2011). In addition, some reports suggest that VTA responses correlated with romantic love scores and inclusion of other in the self (Acevedo et al., 2012; Xu et al., 2012). VTA is the origin of the mesolimbic dopaminergic system, which projects and releases dopamine to the locus coeruleus, prefrontal cortex and anterior cingulate cortex, and it is responsible for the cognitive effects of positive emotion.

\section{Sadness}

Sadness is an emotion that is indicative of loss and helplessness (Motoki and Sugiura, 2018), or it is related to failure to get wanted thing (reward), or punishment to get harmful things ( $\mathrm{Gu}$ et al., 2016). Anterior cingulate cortex (ACC) is related to sadness (Godlewska et al., 2018; Ramirez-Mahaluf et al., 2018a,b). The reason for ACC to be responsible for sadness might be due to the fact that it is the brain side to induce the vocalization for crying response, which is supported by neuroimaging studies. In addition, it is also linked to sadness because of its role in suffering; many studies have suggested ACC is also implicated in pain or the suffering feeling and depression (Taylor et al., 2018). Therefore, ACC is supposed to be the location for frustration, punishment, regret or failure to cope with the situation (Abler et al., 2005). Lateral orbitofrontal area is also involved in unpleasant stimuli, and it is reported that activations in the lateral parts of the orbitofrontal cortex were related to the negative hedonic value.

\section{Fear}

The amygdala is an important limbic structure that has been associated with fear (Anthony et al., 2014; Isosaka et al., 2015; Reynaud et al., 2015; Han et al., 2017). Many fMRI studies support the hypothesis that amygdala is the most important hub in a fear reaction (LeDoux, 1998). Several aspects of fear processing have been attributed to the amygdala, including fear conditioning (Davis, 1992; LeDoux, 2007), initiation of fearinduced behaviors in response to stressors (Weiskrantz, 1956; Blanchard and Blanchard, 1972; Prather et al., 2001; Izquierdo et al., 2005; Machado et al., 2009), and memory creation of fear-related stimuli (Cahill et al., 1995; Hamann, 2001). The importance of the amygdala in initiating the fear emotion and fear-related behaviors has been well described by studying amygdala damage in non-human animals, in which decreased fear-related behaviors have been observed with poor amygdala function (Weiskrantz, 1956; Blanchard and Blanchard, 1972; Prather et al., 2001; Izquierdo et al., 2005; Machado et al., 2009). In addition, clinical observations of a well-characterized human case of bilateral amygdala damage confirmed that amygdala is the location of fear (Feinstein et al., 2011). However, many studies have found that amygdala is involved with many other negative emotions too, such as stress or anger (Siep et al., 2018), which might be due to the emotion flow: fear emotion is transient and can induce several other emotions, such as anger (Zheng et al., 2016). Animals under the influence of fear try to flight away from the threat, however, they will defend themselves, usually aggressively, when flight is impossible or difficult (Papini et al., 2018). This kind of "fight or flight" behavior or "fear and anger" emotion usually happens interchangeably (Zheng et al., 2016). 


\section{Anger}

Orbitofrontal cortex is the location for anger, because of its relation to prey. Many fMRI studies suggest that the interaction between orbitofrontal cortex and amygdala is involved in the regulation of anger (Coccaro et al., 2007; Fulwiler et al., 2012). It is reported that hyperactivity of the interaction between amygdala and orbitofrontal cortex is involved in the altered fear/anger processing at stressful situations (Reynaud et al., 2015). However, some findings also show a hypoactivation in the orbitofrontal cortex (OFC) and the anterior cingulate cortex (ACC), but strong activity in amygdala (Fulwiler et al., 2012; Siep et al., 2018). A meta-analysis study confirmed enhanced activation in the left amygdala to angry stimuli (Bertsch et al., 2018; Krauch et al., 2018). These controversies might be due to the fact that amygdala activity is related to initiation of fear, while activation of the orbitofrontal cortex is involved in the fear extinction (Milad and Rauch, 2007; Siep et al., 2018). Fear extinction is sure to induce anger, which confirmed a previous report that "fight or flight" behavior or "fear and anger" emotion usually happens interchangeably, or that anger is the vent for fear and fear leads to anger (Gu et al., 2016).

\section{Disgust}

The emotion of disgust is typically experienced as a feeling of revulsion elicited by offensive stimulations - e.g., bodily fluids and waste, animal products, rotten food, and certain classes of sexual behavior (such as incest), and is accompanied by a strong desire to throw the eliciting stimulus away (Oaten et al., 2018a,b). Although the insula has been proposed as the seat of disgust processing, which is considered to be distinguishable from other emotive responses - e.g., fear (Wicker et al., 2003), and anger (Wicker et al., 2003; Felmingham et al., 2008; Williams and Bargh, 2008; Koritnik et al., 2009), meta-analysis of imaging data found that the anterior insula is not more active during disgust than other emotions, such as anger (Wager et al., 2007; Oaten et al., 2018a,b). Indeed, disgust in moral situations often induces anger, which suggests that any investigation of the neural correlates of disgust also include the anger related neural network. This is also supported by past studies that report the words "disgust" and "disgusted" evoke feelings associated with anger-related concepts (Oaten et al., 2018a,b), and this is consistent with the report that disgust and anger might be the same kind of basic emotion (Jack et al., 2014).

\section{Surprise}

The surprise emotion alerts the individual of any deviations from expectations, regardless of the outcome value (Litt et al., 2011; Fouragnan et al., 2018). The surprise system works as an attentional mechanism that enables an organism to focus its limited energy on the most salient stimuli (Matsumoto and Hikosaka, 2009; Kahnt et al., 2010; Park et al., 2010). In addition, surprise system can also monitor unexpected information and help plan appropriate behavioral adjustments (Fouragnan et al., 2018). According to meta-analyses of fMRI studies, surprise induced brain regions are predominantly subcortical, including the amygdala and striatum, as well as some cortical regions, such as the ventromedial prefrontal cortex and the cingulate cortex (Behrens et al., 2009; Bartra et al., 2013). This is consistent with the accumulated imaging evidence, which suggest that the amygdala plays a key role in the processing of novel stimuli (Blackford et al., 2010), and also that surprise and fear might be the same basic emotions (Jack et al., 2014).

In all, many imaging data have reported specific loci for specific emotions, such as amygdala for fear (Ohman, 2005), ventromedial frontal cortex for happiness, anterior cingulate cortex for sadness, orbitofrontal cortex for anger (Murphy et al., 2003), insula for disgust (Wicker et al., 2003). Similarly, to previous reports that anger and disgust induce similar facial expressions, "disgust" and "disgusted" evoke feelings associated with anger-related concepts, and both disgust and anger can activate insula. Similarly, fear and surprise also activate similar brain loci, such as amygdala, and surprise can induce ventromedial prefrontal cortex and the cingulate cortex, because happiness can also be involved with surprise.

\section{TWO DIMENSIONS OF BASIC EMOTIONS}

Even though imaging data support the four basic emotions, basic emotions are transient and usually interchangeable, and it might be easy to get confusing data from fMRI studies (Lindquist et al., 2013a), for example, fear and anger emotion usually activate amygdala. Therefore, many people suspected distinct brain regions for the perception of different emotion categories, and hypothesized that it might be easier to find unique neural signatures for the core affects, such as valence and arousal (Wilson-Mendenhall et al., 2013; Bestelmeyer et al., 2017). All emotions are constructed by core affects, including hedonic (pleasure-displeasure) and arousal (restactivated) (Russell, 2003; Gu et al., 2016), which constitute two independent dimensions of a quadrant, where all emotions can find their locations. Different location of each emotion on the quadrant reflects varying amounts of hedonic and arousal properties (Posner et al., 2005; Colibazzi et al., 2010). The horizontal dimension means valence (Watson and Clark, 1988), hedonic dimension (Lang et al., 1993), hedonic tone, liking and other identical items (Gu et al., 2015). The vertical dimension addresses tension and energy (Thayer, 1989), which is due to the unexpected way something happened, and is related to the arousal state of the body, so it is called arousal dimension (Zheng et al., 2016). These two dimensions are typical features of emotions, therefore they can be named as core affects (Sieger et al., 2015). Core affect is a term used to describe the feelings of hedonic pleasure and displeasure with some degree of arousal (Kuppens et al., 2013; Barrett and Russell, 2015); or core affect is the neurophysiological state consciously accessible as the simplest raw feelings, which cannot be reduced to anything simpler (Yik et al., 2011). Izard suggested that "core affect" itself is not a mental state of emotion, merely a feature of emotion (Izard, 2009).

At the dawn of emotional studies, Wilhelm Wundt proposed the three-dimensional theory of emotions from the perspective 

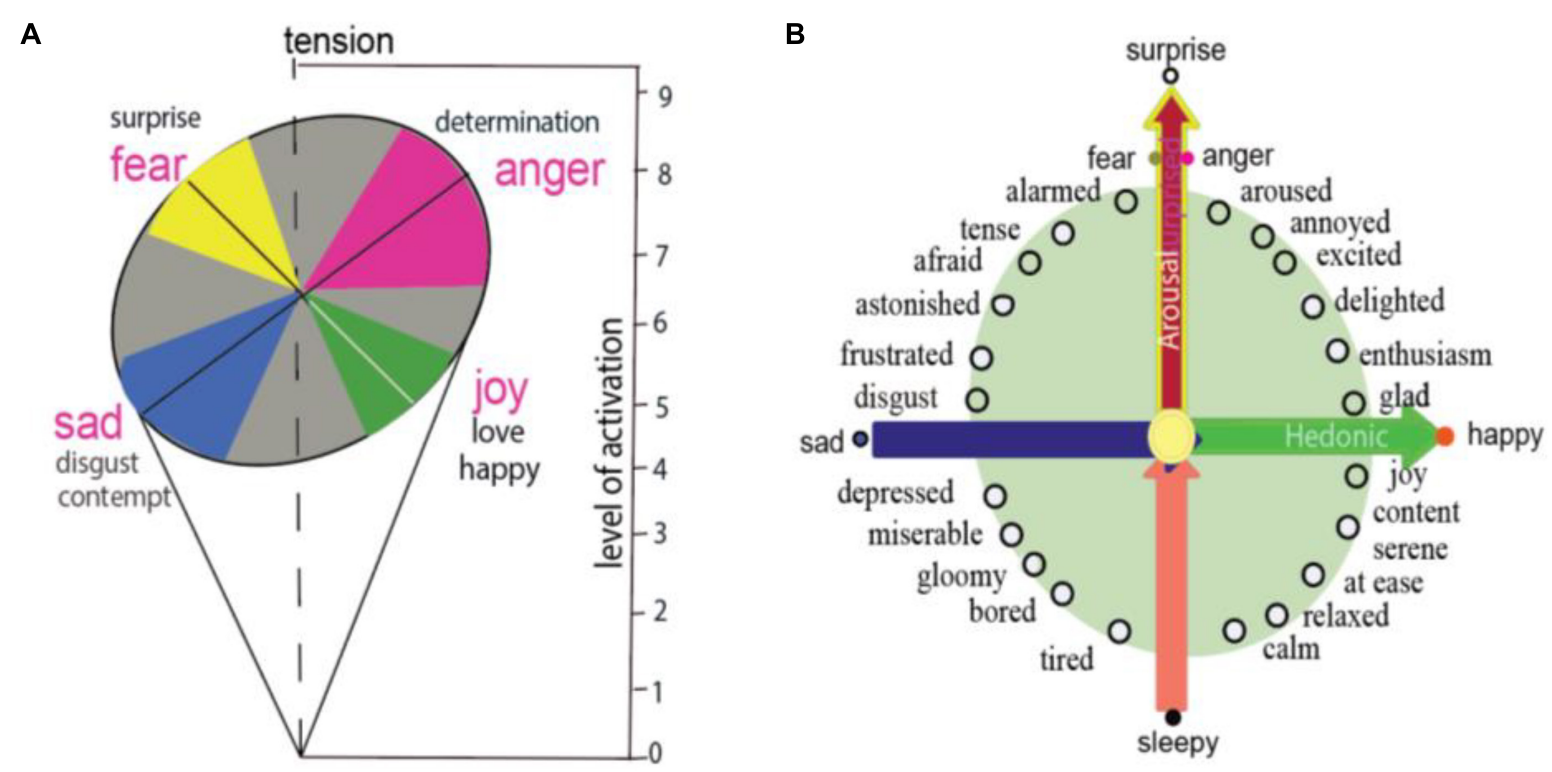

FIGURE 1 | Basic emotion and circumplex. (A) Schlosberg proposed two-dimension of facial expression in a roughly circular surface, whose axes are pleasantness-unpleasantness and attention-rejection. The four basic emotions have different levels of activation, for example, fear and anger can reach higher levels of activation. (B) Circumplex model of emotion proposed that all emotions locate specially on a circle of the circumplex, means that different emotions have different arousal or hedonic parameters. Two core affects of emotions, which are represented on the horizontal dimension and vertical dimension, are induced by two features of a stimulus: the safety value of the stimulus and the hedonic value of the stimulus.

of the construction approach, and suggested that emotions are caused by a set of basic common elements (Lindquist and Barrett, 2012). The three-dimensional theory postulated that human emotions result from fusion of a mixture of six basic forms of feelings: pleasure-displeasure, excitement-inhibition, tensionrelaxation. Later, Schlosberg (1952) used nine-point rating scales for the tense dimension, trying to obtain independent ratings on a large number of posed facial expressions, and found that it might be better to stabilize the ratings and locate each emotion on a roughly circular surface defined by two dimensions (Schlosberg, 1954). He proposed that the whole range of facial expressions may be described in two-dimension of a roughly circular surface, whose axes are pleasantness-unpleasantness and attention-rejection. He proposed that the four emotions representing the polar of the four axes are related to activation, for example: fear and anger can reach higher levels of activation (Figure 1A), which can be compared to the primary colors as "blue-yellow and red-green axes".

Later on, many names have been given to the two dimensions, for example, the circumplex (Figure 1B). The circumplex proposed that every emotion can be spatially represented in a circular arrangement (Posner et al., 2005; Yik et al., 2011), which is anchored on a quadrant with hedonic dimension and arousal dimensions (Kuppens et al., 2013). Barrett proposed that arousal is related to surprise or uncertainty about whether a stimulus will induce threat or reward ( $\mathrm{Gu}$ et al., 2018). The function of arousal is the rapid detection of potential threats and can initiate appropriate approach/avoidance behaviors (fight or flight), as well as sympathetic nervous induced somatic reactions (Colibazzi et al., 2010; Lindquist et al., 2012).

\section{Arousal}

Many psychological constructionists hypothesized that the amygdala is the location for arousal. The amygdala is most likely to be active at surprising situations, which can induce the activity of sympathetic nervous system. In addition, the amygdala has also been found to be activated at many kinds of stimulations, such as novel stimuli (Blackford et al., 2010, 2011; Weierich et al., 2010; Moriguchi et al., 2011), unusual stimuli (Blackford et al., 2011), uncertain stimuli (Herry et al., 2007), or surprise (Holland and Gallagher, 2006; Lee et al., 2006, 2008; Iordanova, 2010; Boll et al., 2013; Vrticka et al., 2014; Kim et al., 2017). Therefore, amygdala activation is not only related to fear, it is related to many highly arousing emotions, such as fear, anger, disgust (Lindquist et al., 2012). Thus, amygdala might be the location for core affect arousal, which is related to uncertain or surprising stimuli.

\section{Valence}

Neuroimaging data support the idea that arousal and valence are encoded separately in the brain (Morrens, 2014). This proposition was developed on the basis of neurophysiological evidence showing that different types of neurons exhibit differential activity in response to reward or surprise (Schultz et al., 1997; Fiorillo, 2013; Fiorillo et al., 2013a,b). A stimulus that evokes emotions has two qualities: its valence (liked or disliked) and its surprise (unexpected or expected). The valence promotes an individual to reinforce an approach/ avoidance behavior, while the arousal component determines the strength of the approach/avoidance behavior (Bartra et al., 2013; Lohani et al., 2017). 


\section{INTEGRATIVE MODEL FOR BASIC EMOTIONS APPROACH AND CONSTRUCTION APPROACH}

Even though basic emotion theory and dimensional theory have been highly influential in the field of affective studies (Hutto et al., 2018), basic emotion and dimensional theory (or called construction approach) has recently been debated (Lindquist et al., 2013b). The construction approach proposes that all the emotions are constructed from more basic "ingredients" - core affects, characterized as valence and arousal (Wilson-Mendenhall et al., 2013), and emotions are grounded in continuous and fluctuating affective states described as pleasant or unpleasant, with some level of arousal. Actually, basic emotions and dimensional studies are not contrary to each other, instead they can help make each other even clearer. Here we propose that the locations of the basic emotions are also constructed by these basic "ingredients," and can also find their locations on the circumplex. The reason for them to be basic is because they locate specially on the circumplex, which indicates the special relationship between the basic emotions and core affects. Fear and anger are on the vertical axis, reflecting the surprising way the stimulus happens (Figure 2; Zheng et al., 2016); while joy and sadness are on the horizontal dimension, depending on the hedonic value of a stimulus. The special locations of these four basic emotions on the dimensions are the reasons why these basic emotions are "basic" (Gu et al., 2016). The specific location on the axis means that they have the highest values of dimension they locate, and it also means that they are not related to the other axis. In addition, fear and anger have no hedonic value and happiness and sadness have no safety value (Gu et al., 2016; Zheng et al., 2016). Of note,

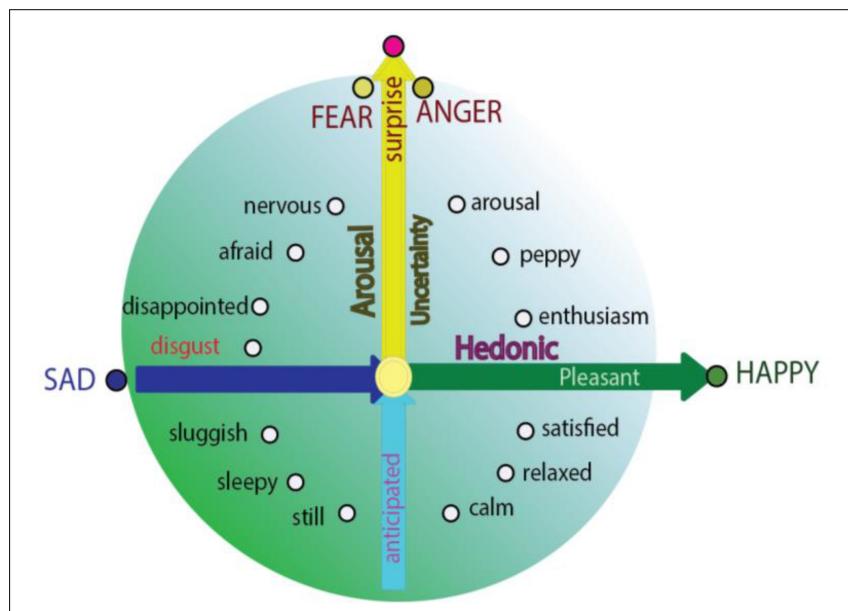

FIGURE 2 | Integrative model for basic emotions and construction approach (dimension theory). Integrative model of emotion proposed that the basic emotions are on the specific locations in the circle of the circumplex; and they are typical emotions which have only one features of core affects: Fear and anger are only related to the safety value of the stimulus, while sadness and joy are only related to the hedonic value of a stimulus; or the "basic emotion" fear and anger have no hedonic value and happiness and sadness have no safety value (Zheng et al., 2016). the basic emotions can easily interact with each other to make other emotions; for example, surprise and happiness can induce enthusiasm (Hu, 2016); or surprise and sadness might induce frustration (Figure 2; Arnott and Elwood, 2009). This is why $\mathrm{Hu}$ Hailan gives the equation: Happiness = reward happened expectation (Hu, 2016). This means the basic emotions used in the experiments might not be so "basic." Thus, we introduce a prerequisite for basic emotions: Basic emotions should locate on the axis of the two emotional dimensions.

\section{Horizontal Dimension-Direction of Behaviors}

Emotion is an innate state, it is a tendency of behavior. Emotions carry behavioral intentions, and the readiness to act in certain ways (Roseman, 1984). The two independent dimensions not only decide two important features of emotions (hedonic value and arousal value), they can also decide the directions of behaviors that they will induce: approach and avoidance direction, and the strength of behavior (LeDoux, 1998; Ledoux and Brown, 2017) (Figure 3). Here, basic emotion induced behaviors can also be arranged in a two-dimension coordinate plane (Figure 3), with the horizontal dimension representing the direction of the behavior, including the approach/avoidance of the behavior, and the vertical dimension shows the agitation of the behavior. Thus, the locations of the emotions on the dimensions can also be decided by the behaviors that they will induce.

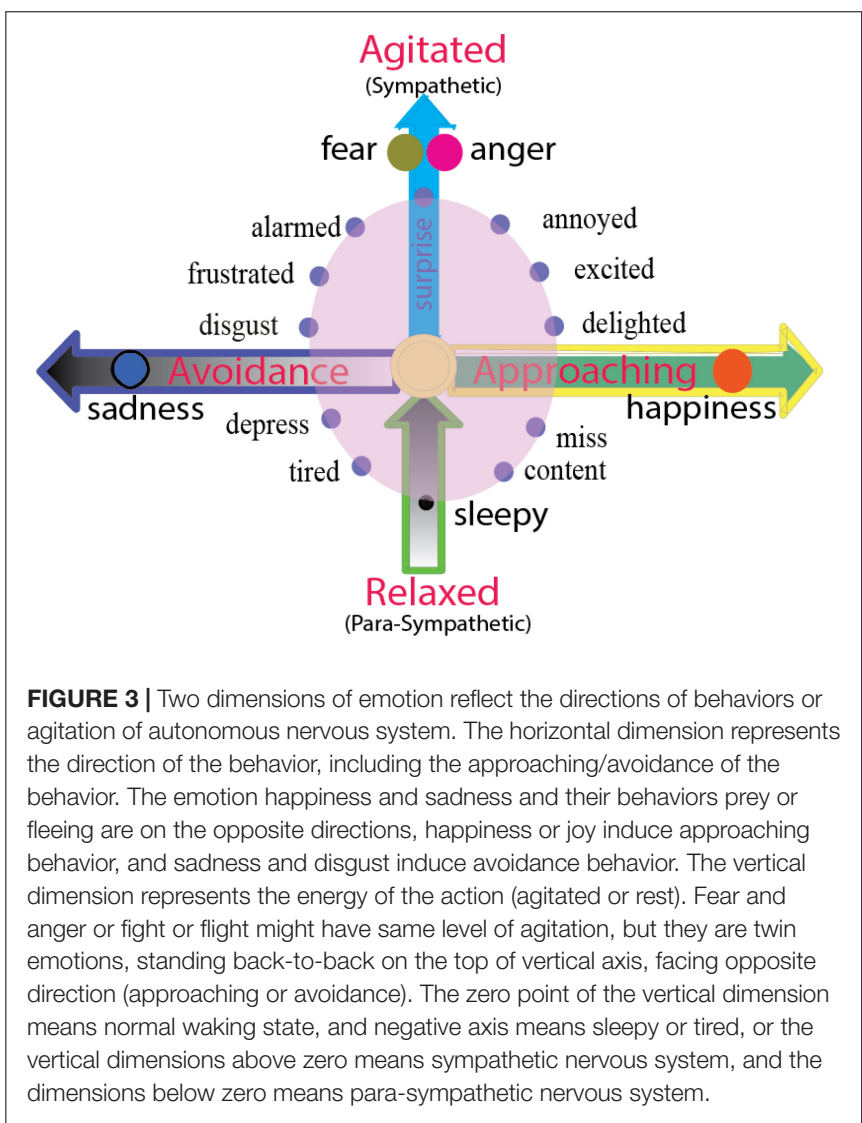


"Fear and anger" induced "fight or flight" but these are different in the direction of the actions: Fear is in the negative direction (Certel et al., 2010), while fight is in the positive direction. Therefore, with happiness and sadness induced behaviors that are characteristic of prey or fleeing: Prey is in the positive direction while fleeing in the negative direction.

\section{Vertical Dimension-Agitation of Behaviors}

While the horizontal dimension shows the direction of the behavior, the vertical dimension shows the agitation of the behavior, or the activities of autonomous nervous systems. The location above zero point means the activity of sympathetic nervous system, while the location below zero means the activity of the parasympathetic nervous system. "Fear and anger" induced "fight or flight" reflects the highest agitation of the sympathetic nervous system. The zero point means the normal waking state, and the negative axis means lethargy or sleepy. Freezing is in the special location " 0 " on the two-dimension coordinate plane (Figure 3). The fear and anger might have similar agitation, but they are different in the direction of the actions, fear is in the negative valence (Certel et al., 2010), while fight is in the positive direction. The vertical dimension represents the energy of the action (agitated or rest), so the fear and anger have the same volume of arousal.

\section{Fear and Anger Are Twin Emotions}

Appraisal theory proposed that emotions are induced by the appraisal of a stimulus. Lazarus suggested that after meeting with a stimulus, the individual would first have an automatic, unconscious, and fast activating evaluation of the stimulus (Figure 4). Lazarus proposed that the primary appraisal is an unconscious judgment about the potential threat to an individual from a stressor (Lazarus, 1999). If the stimulus induces a threat, then the secondary appraisal will be induced. The secondary appraisal is conscious and concerned with coping (Lazarus, 1999; Zheng et al., 2016). Ledox also propose that the threat usually first induces fast unconscious fearful emotions, then induces angry emotions through cognitive comparisons (LeDoux, 1996). Thus, fear is related with uncertainty about the situation; and anger is related with trying to control the situation (Moons et al., 2010; Wang et al., 2017, 2018). The coping methods can be angry fight (having sufficient resources) or fearful flight (having insufficient resources). Therefore, we propose that fear can induce anger, while anger is the vent of fear ( $\mathrm{Gu}$ et al., 2016; Zheng et al., 2016). Both fear and anger can aid survival by influencing an organism to either flight or fight for survival (LeDoux, 1998; Ledoux and Brown, 2017). Fear and anger are activated by norepinephrine systems, and they expressed similar sympathetic nervous activation (LeDoux, 1998; Zheng et al., 2016; Ledoux and Brown, 2017).

After coping with the stressful situation with direct actions, Lazarus suggested a kind of cognitive reappraisal processes: positive emotions will be induced after successfully coping with the situation, which can be named eudaimonic happiness (Berridge and Kringelbach, 2011); or negative emotions will be

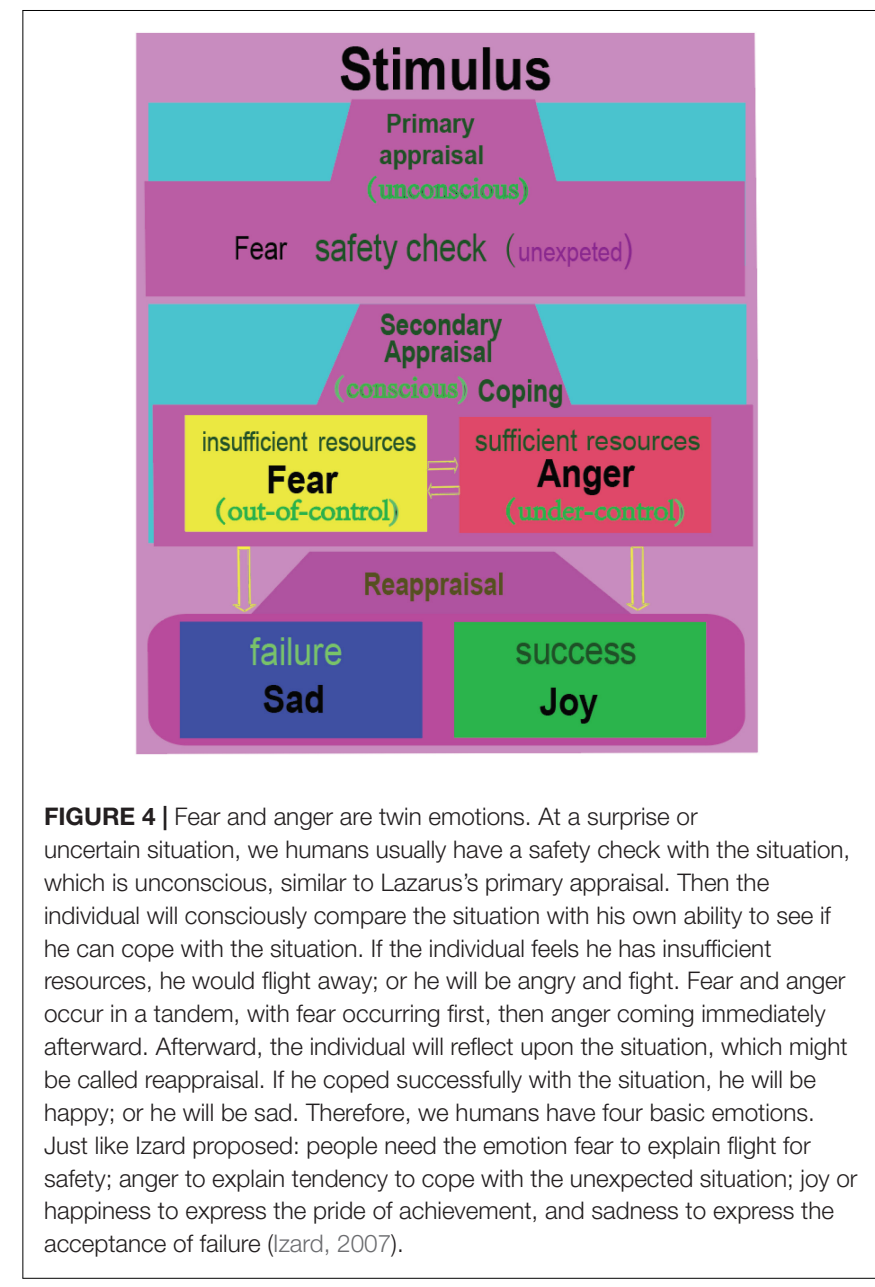

induced at failure to cope with the situation, which can be named sadness (Aldwin, 1994; Lazarus, 1999). The reappraisal can also be affected by cognition, therefore, positive reappraisal can induce better moods after stressful situations (Gross, 2002; Ochsner et al., 2002; Troy et al., 2010; Wang et al., 2017). The term "eudaimonia" is related to subjective feelings that an individual can feel when he is engaged in activities that are related to his skills or abilities contributing to his personal ambitions and life goals (Ryff, 2014, 2018). So when something unexpected occurs, the individual will first evaluate its threat (fear/anger) and next evaluate its hedonic value (happy/sad) (Gu et al., 2015, 2018). Indeed, basic emotions are transient and interchangeable, which makes it difficult to be differentiated with fMRI studies, which has temporal limitations (Kringelbach, 2005).

\section{Four Basic Emotions on Two Dimensions}

Many psychologists have proposed that disgust and surprise are basic emotions, such as Ekman, Plutchik. However, disgust is kind of strong dislike, or disgust has something to do with the arousal. This means disgust does not locate on the hedonic axis, instead it is biased toward the arousal dimension. Surprise was named as one basic emotion by many psychologists, it actually might be a core affect instead of an emotion. Surprise seems like a 
property of a stimulus, instead of an emotion. Therefore, surprise might be a better name for the vertical dimension, or surprise should be a core affect instead of a basic emotion.

All in all, we humans have four basic emotions: Happiness and sadness represent the horizontal dimension, reflecting the hedonic value of the stimulus (Figure 2); while fear and anger are on the vertical axis, depending on the surprising way the stimulus happens. Just like what Izard proposed: People need the emotion fear to explain flight for safety; anger to explain tendency to cope with the unexpected situation; joy or happiness to express the pride of achievement, and sadness to express the acceptance of failure (Izard, 2007). With this in mind, it might be easier to understand the fMRI results, which found that some basic emotions induced similar brain activities, for fear, anger and surprise located on the same location of the vertical dimension. This might be the reason that fMRI studies found that activation of limbic and paralimbic brain regions are not specific to special basic emotions (for example, amygdala is not for fear, anger, or surprise), instead they are related to the core affects (Kragel and LaBar, 2016); or the orbitofrontal cortex responds not only to specific instances of positive emotions, instead they respond to hedonic value, and can be named as "salience network". In addition, the analyses found that subjective rating of valence predicted the similar responses in mesolimbic dopaminergic systems (Kamitani and Tong, 2005; Lindquist et al., 2012).

\section{CONCLUSION}

The basic emotion theory hypothesizes that basic emotion (and the emotions that are derived from this basic emotion) is produced by the activity of a defined brain locus or an anatomically defined network (Farinelli et al., 2015). Recently, this approach has incorporated efforts to map basic emotions to brain networks that comprise basic emotions (fear, anger, happiness and sadness) (Cowen and Keltner, 2018; Selvaraj et al., 2018). However, fMRI studies cannot achieve consistent imaging data for specific brain areas for a specific emotion.

\section{REFERENCES}

Abler, B., Walter, H., and Erk, S. (2005). Neural correlates of frustration. Neuroreport 16, 669-672. doi: 10.1097/00001756-200505120-00003

Acevedo, B. P., Aron, A., Fisher, H. E., and Brown, L. L. (2012). Neural correlates of long-term intense romantic love. Soc. Cogn. Affect. Neurosci. 7, 145-159. doi: $10.1093 /$ scan/nsq092

Aldwin, C. M. (1994). Stress, Coping, and Development. New York, NY: The Guildford Press.

An, S., Ji, L., Marks, M., and Zhang, Z. (2017). Two sides of emotion: exploring positivity and negativity in six basic emotions across cultures. Front. Psychol. 8:610. doi: 10.3389/fpsyg.2017.00610

Anthony, T., Dee, N., Bernard, A., Lerchner, W., Heintz, N., Anderson, D. J., et al. (2014). Control of stress-induced persistent anxiety by an extraamygdala septohypothalamic circuit. Cell 156, 522-536. doi: 10.1016/j.cell.2013. 12.040

Arnott, G., and Elwood, R. (2009). Probing aggressive motivation in a cichilid fish. Biol. Lett. 5, 762-764. doi: 10.1098/rsbl.2009.0526

Barrett, L., and Russell, J. (2015). They Psychological Construction of Emotion. New York, NY: Guildofrd press.
Thus, many researchers suggested an alternative way to explain it: the psychological constructionist model of emotion, hoping that we can get consistent brain activities for core affects in fMRI experiments, or there are specific neural structures that are involved in arousal and hedonic value. Even though hedonic value can achieve consistent activities in the anterior insular, OFC, caudate, thalamus and anterior cingulate, arousal values still demonstrate some trouble in the fMRI studies (Lewis et al., 2007; Kuppens et al., 2013; Lindquist et al., 2013a).

Here we have reviewed brain imaging and neuropsychological data, and addressed this question with an integrative model. In this model, we proposed that basic emotions are not contrary to the dimensional studies of emotions (core affect). Instead, basic emotions can be explained more clearly with the dimensional studies. We also give a criteria for basic emotions: Basic emotion should locate on the axis in the dimensions of emotion, and only represent one typical core affect (arousal or valence). Therefore, we proposed four basic emotions: joy-on positive axis of hedonic dimension, sadness-on negative axis of hedonic dimension, fear and anger which are twin emotions and locate on the top of vertical dimensions. This new model for basic emotions and the construction model of emotions is promised to improve and reformulate neurobiological models of basic emotions.

\section{AUTHOR CONTRIBUTIONS}

SG and FW designed the manuscript. SG, FW, EW, YT, and JH wrote the manuscript. CC revised the manuscript.

\section{FUNDING}

This work was supported by a grant from Foundation of Humanities and Social Science in Ministry of Education in China (FW, 19YJAZH083). FW is also a member of Jiangsu Six Talent Peak (2015YY006).
Barrett, L., and Satpute, A. (2013). Large-scale brain networks in affective and social neuroscience: towards an integrative functional architecture of the brain. Curr. Opin. Neurobiol. 23, 361-372. doi: 10.1016/j.conb.2012.12.012

Bartra, O., McGuire, J. T., and Kable, J. W. (2013). The valuation system: a coordinate-based meta-analysis of BOLD fMRI experiments examining neural correlates of subjective value. Neuroimage 76, 412-427. doi: 10.1016/j. neuroimage.2013.02.063

Beer, J. S., Heerey, E. A., Keltner, D., Scabini, D., and Knight, R. T. (2003). The regulatory function of self-conscious emotion: insights from patients with orbitofrontal damage. J. Pers. Soc. Psychol. 85, 594-604. doi: 10.1037/0022-3514. 85.4.594

Behrens, T. E., Woolrich, M. W., Walton, M. E., and Rushworth, M. F. (2009). Learning the value of information in an uncertain world. Nat. Neurosci. 10, 1214-1221. doi: 10.1038/nn1954

Berridge, K. C., and Kringelbach, M. L. (2011). Building a neuroscience of pleasure and well-being. Psychol. Well Being 1, 1-3.

Bertsch, K., Krauch, M., Roelofs, K., Cackowski, S., Herpertz, S. C., Volman, I., et al. (2018). Out of control? Acting out anger is associated with deficient prefrontal emotional action control in male patients with borderline personality disorder. Neuropharmacology. 
Bestelmeyer, P. E. G., Kotz, S. A., and Belin, P. (2017). Effects of emotional valence and arousal on the voice perception network. Soc. Cogn. Affect. Neurosci. 12, 1351-1358. doi: 10.1093/scan/nsx059

Blackford, J. U., Avery, S. N., Cowan, R. L., Shelton, R. C., and Zald, D. H. (2011). Sustained amygdala response to both novel and newly familiar faces characterizes inhibited temperament. Soc. Cogn. Affect. Neurosci. 6, 621-629. doi: 10.1093/scan/nsq073

Blackford, J. U., Buckholtz, J. W., Avery, S. N., and Zald, D. H. (2010). A unique role for the human amygdala in novelty detection. Neuroimage 50, 1188-1193. doi: 10.1016/j.neuroimage.2009.12.083

Blanchard, D. C., and Blanchard, R. J. (1972). Innate and conditioned reactions to threat in rats with amygdaloid lesions. J. Comp. Physiol. Psychol. 81, 281-290. doi: 10.1037/h0033521

Boll, S., Gamer, M., Gluth, S., Finsterbusch, J., and Buchel, C. (2013). Separate amygdala subregions signal surprise and predictiveness during associative fear learning in humans. Eur. J. Neurosci. 37, 758-767. doi: 10.1111/ejn.12094

Burke, K. A., Franz, T. M., Miller, D. N., and Schoenbaum, G. (2007). Conditioned reinforcement can be mediated by either outcome-specific or general affective representations. Front. Integr. Neurosci. 1:2. doi: 10.3389/neuro.07.002.2007

Burke, K. A., Franz, T. M., Miller, D. N., and Schoenbaum, G. (2008). The role of the orbitofrontal cortex in the pursuit of happiness and more specific rewards. Nature 454, 340-344. doi: 10.1038/nature06993

Burke, K. A., Takahashi, Y. K., Correll, J., Brown, P. L., and Schoenbaum, G. (2009). Orbitofrontal inactivation impairs reversal of Pavlovian learning by interfering with 'disinhibition' of responding for previously unrewarded cues. Eur. J. Neurosci. 30, 1941-1946. doi: 10.1111/j.1460-9568.2009.06992.x

Cahill, L., Babinsky, R., Markowitsch, H. J., and McGaugh, J. L. (1995). The amygdala and emotional memory. Nature 377, 295-296.

Celeghin, A., Diano, M., Bagnis, A., Viola, M., and Tamietto, M. (2017). Basic emotions in human neuroscience: neuroimaging and beyond. Front. Psychol. 8:1432. doi: 10.3389/fpsyg.2017.01432

Certel, S. J., Leung, A., Lin, C. Y., Perez, P., Chiang, A. S., Kravitz, E. A., et al. (2010). Octopamine neuromodulatory effects on a social behavior decisionmaking network in Drosophila males. PLoS One 5:e13248. doi: 10.1371/journal. pone.0013248

Clark-Polner, E., Johnson, T. D., and Barrett, L. F. (2017). Multivoxel pattern analysis does not provide evidence to support the existence of basic emotions. Cereb. Cortex 27, 1944-1948.

Clore, G. L., and Ortony, A. (2013). Psychological construction in the OCC model of emotion. Emot. Rev. 5, 335-343. doi: 10.1177/1754073913489751

Coccaro, E. F., McCloskey, M. S., Fitzgerald, D. A., and Phan, K. L. (2007). Amygdala and orbitofrontal reactivity to social threat in individuals with impulsive aggression. Biol. Psychiatry 62, 168-178. doi: 10.1016/j.biopsych. 2006.08.024

Colibazzi, T., Posner, J., Wang, Z., Gorman, D., Gerber, A., Yu, S., et al. (2010). Neural systems subserving valence and arousal during the experience of induced emotions. Emotion 10, 377-389. doi: 10.1037/a0018484

Colmbetti, G. (2014). The Feeling Body: Affective Science Meets the Enactive Mind. Cambridge, MA: MIT press.

Colombetti, G. (2014). The Feeding Body: Affective Science Meet the Enactive Mind. Cambfidge, MA: MIT press.

Cowen, A. S., and Keltner, D. (2018). Clarifying the conceptualization, dimensionality, and structure of emotion: response to barrett and colleagues. Trends Cogn. Sci. 22, 274-276. doi: 10.1016/j.tics.2018.02.003

Damasio, A., and Carvalho, G. B. (2013). The nature of feelings: evolutionary and neurobiological origins. Nat. Rev. Neurosci. 14, 143-152. doi: 10.1038/nrn 3403

Davis, M. (1992). The role of the amygdala in fear and anxiety. Annu. Rev. Neurosci. 15, 353-375. doi: 10.1146/annurev.neuro.15.1.353

Ekman, P. (1992). An arugment for basic emotions. Cognit. Emot. 6, 169-200.

Etkin, A., Buchel, C., and Gross, J. J. (2015). The neural bases of emotion regulation. Nat. Rev. Neurosci. 16, 693-700. doi: 10.1038/nrn4044

Etkin, A., Buchel, C., and Gross, J. J. (2016). Emotion regulation involves both model-based and model-free processes. Nat. Rev. Neurosci. 17:532. doi: 10.1038/ nrn.2016.79

Farinelli, M., Panksepp, J., Gestieri, L., Maffei, M., Agati, R., Cevolani, D., et al. (2015). Do brain lesions in stroke affect basic emotions and attachment? J. Clin. Exp. Neuropsychol. 37, 595-613. doi: 10.1080/13803395.2014.991279
Fehr, B., and Russell, J. A. (1984). Concept of emotion viewed from a prototype perspective. J. Exp. Psychol. Gen. 113, 464-486. doi: 10.1037//0096-3445.113.3. 464

Feinstein, J. S., Adolphs, R., Damasio, A., and Tranel, D. (2011). The human amygdala and the induction and experience of fear. Curr. Biol. 21, 34-38. doi: 10.1016/j.cub.2010.11.042

Felmingham, K., Kemp, A. H., Williams, L., Falconer, E., Olivieri, G., Peduto, A., et al. (2008). Dissociative responses to conscious and non-conscious fear impact underlying brain function in post-traumatic stress disorder. Psychol. Med. 38, 1771-1780. doi: 10.1017/s0033291708002742

Fiorillo, C. D. (2013). Two dimensions of value: dopamine neurons represent reward but not aversiveness. Science 341, 546-549. doi: 10.1126/science.1238699 doi: 10.1126/science.1238699 doi: 10.1126/science.1238699

Fiorillo, C. D., Song, M. R., and Yun, S. R. (2013a). Multiphasic temporal dynamics in responses of midbrain dopamine neurons to appetitive and aversive stimuli. J. Neurosci. 33, 4710-4725. doi: 10.1523/jneurosci.3883-12.2013

Fiorillo, C. D., Yun, S. R., and Song, M. R. (2013b). Diversity and homogeneity in responses of midbrain dopamine neurons. J. Neurosci. 33, 4693-4709. doi: 10.1523/jneurosci.3886-12.2013

Fouragnan, E., Retzler, C., and Philiastides, M. G. (2018). Separate neural representations of prediction error valence and surprise: evidence from an fMRI meta-analysis. Hum. Brain Mapp. 39, 2887-2906. doi: 10.1002/hbm. 24047

Fulwiler, C. E., King, J. A., and Zhang, N. (2012). Amygdala-orbitofrontal restingstate functional connectivity is associated with trait anger. Neuroreport 23, 606-610. doi: 10.1097/00001756-201207110-00006

Godlewska, B. R., Browning, M., Norbury, R., Igoumenou, A., Cowen, P. J., Harmer, C. J., et al. (2018). Predicting treatment response in depression: the role of anterior cingulate cortex. Int. J. Neuropsychopharmacol. 21, 988-996. doi: 10.1093/ijnp/pyy069

Grabenhorst, F., and Rolls, E. T. (2011). Value, pleasure and choice in the ventral prefrontal cortex. Trends Cogn. Sci. 15, 56-67. doi: 10.1016/j.tics.2010.12.004

Gross, J. J. (2002). Emotion regulation: affective, cognitive, and social consequences. Psychophysiology 39, 281-291. doi: 10.1017/s0048577201393198

Gu, S., Mengdan, G., Yaoyao, Y., Fushun, W., and Huang, J. H. (2018). The neural mechanism underlying cognitive and emotional processes in creativity. Front. Psychol. 9:1924. doi: 10.3389/fpsyg.2018.01924

Gu, S., Wang, F., Yuan, T., Guo, B., and Huang, H. (2015). Differentiation of primary emotions through neuromodulators: review of literature. Int. J. Neurol. Res. 1, 43-50. doi: 10.17554/j.issn.2313-5611.2015.01.19

Gu, S., Wang, W., Wang, F., and Huang, J. H. (2016). Neuromodulator and emotion biomarker for stress induced mental disorders. Neural Plast. 2016:2609128.

Hamann, S. (2001). Cognitive and neural mechanisms of emotional memory. Trends Cognit. Sci. 5, 394-400. doi: 10.1016/s1364-6613(00)01707-1

Hamann, S. (2012). Mapping discrete and dimensional emotions onto the brain: controversies and consensus. Trends Cogn. Sci. 16, 458-466. doi: 10.1016/j.tics. 2012.07.006

Han, W., Tellez, L. A., Rangel, M. J. Jr., Motta, S. C., Zhang, X., Perez, I. O., et al. (2017). Integrated control of predatory hunting by the central nucleus of the amygdala. Cell 168, 311-324.

Hay, A. C., Sheppes, G., Gross, J. J., and Gruber, J. (2015). Choosing how to feel: emotion regulation choice in bipolar disorder. Emotion 15, 139-145. doi: 10.1037/emo0000024

Herry, C., Bach, D. R., Esposito, F., Di Salle, F., Perrig, W. J., Scheffler, K., et al. (2007). Processing of temporal unpredictability in human and animal amygdala. J. Neurosci. 27, 5958-5966. doi: 10.1523/jneurosci.5218-06.2007

Holland, P. C., and Gallagher, M. (2006). Different roles for amygdala central nucleus and substantia innominata in the surprise-induced enhancement of learning. J. Neurosci. 26, 3791-3797. doi: 10.1523/jneurosci.0390-06. 2006

Hu, H. (2016). Reward and aversion. Annu. Rev. Neurosci. 39, 297-324.

Hutto, D. D., Robertson, I., and Kirchhoff, M. D. (2018). A new, better BET: rescuing and revising basic emotion theory. Front. Psychol. 9:1217. doi: 10.3389/ fpsyg.2018.01217

Iordanova, M. D. (2010). Dopamine transmission in the amygdala modulates surprise in an aversive blocking paradigm. Behav. Neurosci. 124, 780-788. doi: 10.1037/a0021111 
Isosaka, T., Matsuo, T., Yamaguchi, T., Funabiki, K., Nakanishi, S., Kobayakawa, R., et al. (2015). Htr2a-expressing cells in the central amygdala control the hierarchy between innate and learned fear. Cell 163, 1153-1164. doi: 10.1016/j. cell.2015.10.047

Izard, C. E. (2007). Basic emotions, natural kinds, emotion schemas, and a new paradigm. Perspect. Psychol. Sci. 2, 260-280. doi: 10.1111/j.1745-6916.2007. 00044.x

Izard, C. E. (2009). Emotion theory and research: highlights, unanswered questions, and emerging issues. Annu. Rev. Psychol. 60, 1-25. doi: 10.1146/ annurev.psych.60.110707.163539

Izquierdo, A., Suda, R. K., and Murray, E. A. (2005). Comparison of the effects of bilateral orbital prefrontal cortex lesions and amygdala lesions on emotional responses in rhesus monkeys. J. Neurosci. 25, 8534-8542. doi: 10. 1523/jneurosci.1232-05.2005

Jack, R., Garrod, O., and Schyns, P. (2014). Dynamic facial expressions of emotion transmit an evolving hierarchy of signals over time. Curr. Biol. 24, 187-192. doi: 10.1016/j.cub.2013.11.064

Kahnt, T., Heinzle, J., Park, S. Q., and Haynes, J. D. (2010). The neural code of reward anticipation in human orbitofrontal cortex. Proc. Natl. Acad. Sci. U.S.A. 107, 6010-6015. doi: 10.1073/pnas.0912838107

Kamitani, Y., and Tong, F. (2005). Decoding the visual and subjective contents of the human brain. Nat. Neurosci. 8, 679-685. doi: 10.1038/nn1444

Kim, M. J., Mattek, A. M., Bennett, R. H., Solomon, K. M., Shin, J., Whalen, P. J., et al. (2017). Human amygdala tracks a feature-based valence signal embedded within the facial expression of surprise. J. Neurosci. 37, 9510-9518. doi: 10.1523/jneurosci.1375-17.2017

Koritnik, B., Azam, S., Andrew, C. M., Leigh, P. N., and Williams, S. C. (2009). Imaging the brain during sniffing: a pilot fMRI study. Pulm. Pharmacol. Ther. 22, 97-101. doi: 10.1016/j.pupt.2008.10.009

Kragel, P. A., and LaBar, K. S. (2016). Decoding the nature of emotion in the brain. Trends Cogn. Sci. 20, 444-455. doi: 10.1016/j.tics.2016.03.011

Krauch, M., Ueltzhöffer, K., Brunner, R., Kaess, M., Hensel, S., Herpertz, S. C., et al. (2018). Heightened salience of anger and aggression in female adolescents with borderline personality disorder-a script-based fMRI study. Front. Behav. Neurosci. 12:57. doi: 10.3389/fnbeh.2018.00057

Krebs, R. M., Heipertz, D., Schuetze, H., and Duzel, E. (2011). Novelty increases the mesolimbic functional connectivity of the substantia nigra/ventral tegmental area (SN/VTA) during reward anticipation: evidence from high-resolution fMRI. Neuroimage 58, 647-655. doi: 10.1016/j.neuroimage.2011.06.038

Kringelbach, M. L. (2005). The human orbitofrontal cortex: linking reward to hedonic experience. Nat. Rev. Neurosci. 6, 691-702. doi: 10.1038/nrn1747

Kuppens, P., Tuerlinckx, F., Russell, J. A., and Barrett, L. F. (2013). The relation between valence and arousal in subjective experience. Psychol. Bull. 139, 917-940. doi: 10.1037/a0030811

Lang, P. J., Greenwald, M. K., Bradley, M. M., and Hamm, A. O. (1993). Looking at pictures: affective, facial, visceral, and behavioral reactions. Psychophysiology 30, 261-273. doi: 10.1111/j.1469-8986.1993.tb03352.x

Lazarus, R. S. (1999). Stress and Emotion: A New Synthesis. New York: Springer.

Ledoux, and Brown, R. (2017). A higher-order theory of emotional consciousness. Proc. Natl. Acad. Sci. U.S.A. 114, E2016-E2025.

LeDoux, J. (1996). The Emotional Brain: The Mysterous Underpinnings of Emotional Life. New York, NY: Simon \& Schuster.

LeDoux, J. (1998). Fear and the brain: where have we been, and where are we going? Biol. Psychiatry 44, 1229-1238. doi: 10.1016/s0006-3223(98)00282-0

LeDoux, J. (2007). The amygdala. Curr. Biol. 17, R868-R874.

Lee, H. J., Youn, J. M., Gallagher, M., and Holland, P. C. (2008). Temporally limited role of substantia nigra-central amygdala connections in surpriseinduced enhancement of learning. Eur. J. Neurosci. 27, 3043-3049. doi: 10.1111/ j.1460-9568.2008.06272.x

Lee, H. J., Youn, J. M., O, M. J., Gallagher, M., and Holland, P. C. (2006). Role of substantia nigra-amygdala connections in surprise-induced enhancement of attention. J. Neurosci. 26, 6077-6081. doi: 10.1523/jneurosci.1316-06.2006

Lewis, P. A., Critchley, H. D., Rotshtein, P., and Dolan, R. J. (2007). Neural correlates of processing valence and arousal in affective words. Cereb. Cortex 17, 742-748. doi: 10.1093/cercor/bhk024

Lindquist, K., and Barrett, L. (2012). A functional architecture of the human brain: emerging insights from the science of emotion. Trends Cogn. Sci. 16, 533-540. doi: 10.1016/j.tics.2012.09.005
Lindquist, K., Wager, T., Kober, H., Bliss-Moreau, E., and Barrett, L. (2012). The brain basis of emotion: a meta-analytic review. Behav. Brain Sci. 35, 121-143. doi: $10.1017 /$ s0140525x11000446

Lindquist, K. A., Gendron, M., Oosterwijk, S., and Barrett, L. F. (2013a). Do people essentialize emotions? Individual differences in emotion essentialism and emotional experience. Emotion 13, 629-644. doi: 10.1037/a003 2283

Lindquist, K. A., Siegel, E. H., Quigley, K. S., and Barrett, L. F. (2013b). The hundred-year emotion war: are emotions natural kinds or psychological constructions? Comment on Lench, Flores, and Bench (2011). Psychol. Bull. 139, 255-263. doi: 10.1037/a0029038

Litt, A., Plassmann, H., Shiv, B., and Rangel, A. (2011). Dissociating valuation and saliency signals during decision-making. Cereb. Cortex 21, 95-102. doi: 10.1093/cercor/bhq065

Lohani, S., Poplawsky, A. J., Kim, S. G., and Moghaddam, B. (2017). Unexpected global impact of VTA dopamine neuron activation as measured by opto-fMRI. Mol. Psychiatry 22, 585-594. doi: 10.1038/mp.2016.102

Luo, Y., Qi, S., Chen, X., You, X., Huang, X., Yang, Z., et al. (2017). Pleasure attainment or self-realization: the balance between two forms of well-beings are encoded in default mode network. Soc. Cogn. Affect Neurosci. 12, 1678-1686. doi: $10.1093 /$ scan/nsx078

Machado, C. J., Kazama, A. M., and Bachevalier, J. (2009). Impact of amygdala, orbital frontal, or hippocampal lesions on threat avoidance and emotional reactivity in nonhuman primates. Emotion (Washington, D.C.) 9, 147-163. doi: $10.1037 / \mathrm{a} 0014539$

Matsumoto, M., and Hikosaka, O. (2009). Two types of dopamine neuron distinctly convey positive and negative motivational signals. Nature 459, 837-841. doi: 10.1038/nature08028

Milad, M. R., and Rauch, S. L. (2007). The role of the orbitofrontal cortex in anxiety disorders. Ann. N. Y. Acad. Sci. 1121, 546-561. doi: 10.1196/annals.14 01.006

Milyavsky, M., Webber, D., Fernandez, J. R., Kruglanski, A. W., Goldenberg, A., Suri, G., et al. (2018). To reappraise or not to reappraise? Emotion regulation choice and cognitive energetics. Emotion .

Moons, W. G., Eisenberger, N. I., and Taylor, S. E. (2010). Anger and fear responses to stress have different biological profiles. Brain Behav. Immun. 24, 215-219. doi: 10.1016/j.bbi.2009.08.009

Moriguchi, Y., Negreira, A., Weierich, M., Dautoff, R., Dickerson, B. C., Wright, C. I., et al. (2011). Differential hemodynamic response in affective circuitry with aging: an FMRI study of novelty, valence, and arousal. J. Cogn. Neurosci. 23, 1027-1041. doi: 10.1162/jocn.2010.21527

Morrens, J. (2014). Dopamine neurons coding prediction errors in reward space, but not in aversive space: a matter of location? J. Neurophysiol. 112, 1021-1024. doi: $10.1152 /$ jn. 00751.2013

Motoki, K., and Sugiura, M. (2018). Disgust, sadness, and appraisal: disgusted consumers dislike food more than sad ones. Front. Psychol. 9:76. doi: 10.3389/ fpsyg.2018.00076

Murphy, F. C., Nimmo-Smith, I., and Lawrence, A. D. (2003). Functional neuroanatomy of emotions: a meta-analysis. Cognit. Affect. Behav. Neurosci. 3, 207-233. doi: $10.3758 /$ cabn.3.3.207

Oaten, M., Stevenson, R. J., Tapp, C., Case, T. I., and Cousins, A. (2018a). The role of disgust in male sexual decision-making. Front. Psychol. 9:2602. doi: 10.3389/fpsyg.2018.02602

Oaten, M., Stevenson, R. J., Williams, M. A., Rich, A. N., Butko, M., Case, T. I., et al. (2018b). Moral violations and the experience of disgust and anger. Front. Behav. Neurosci. 12:179. doi: 10.3389/fnbeh.2018.00179

Ochsner, K. N., Bunge, S. A., Gross, J. J., and Gabrieli, J. D. E. (2002). Rethinking feelings: an FMRI study of the cognitive regulation of emotion. J. Cogn. Neurosci. 14, 1215-1229. doi: 10.1162/089892902760807212

Ohman, A. (2005). The role of the amygdala in human fear: automatic detection of threat. Psychoneuroendocrinology 30, 953-958. doi: 10.1016/j.psyneuen.2005. 03.019

Papini, M. R., Penagos-Corzo, J. C., and Perez-Acosta, A. M. (2018). Avian emotions: comparative perspectives on fear and frustration. Front. Psychol. 9:2707. doi: 10.3389/fpsyg.2018.02707

Park, S. Q., Kahnt, T., Beck, A., Cohen, M. X., Dolan, R. J., Wrase, J., et al. (2010). Prefrontal cortex fails to learn from reward prediction errors in alcohol dependence. J. Neurosci. 30, 7749-7753. doi: 10.1523/jneurosci.5587-09.2010 
Phan, K. L., Wager, T., Taylor, S. F., and Liberzon, I. (2002). Functional neuroanatomy of emotion: a meta-analysis of emotion activation studies in PET and fMRI. Neuroimage 16, 331-348. doi: 10.1006/nimg.2002.1087

Posner, J., Russell, J. A., and Peterson, B. S. (2005). The circumplex model of affect: an integrative approach to affective neuroscience, cognitive development, and psychopathology. Dev. Psychopathol. 17, 715-734.

Prather, M. D., Lavenex, P., Mauldin-Jourdain, M. L., Mason, W. A., Capitanio, J. P., Mendoza, S. P., et al. (2001). Increased social fear and decreased fear of objects in monkeys with neonatal amygdala lesions. Neuroscience 106, 653-658. doi: 10.1016/s0306-4522(01)00445-6

Ramirez-Mahaluf, J. P., Perramon, J., Otal, B., Villoslada, P., and Compte, A. (2018a). Author correction: subgenual anterior cingulate cortex controls sadness-induced modulations of cognitive and emotional network hubs. Sci. Rep. 8:11237.

Ramirez-Mahaluf, J. P., Perramon, J., Otal, B., Villoslada, P., and Compte, A. (2018b). Subgenual anterior cingulate cortex controls sadness-induced modulations of cognitive and emotional network hubs. Sci. Rep. 8:8566.

Reynaud, E., Guedj, E., Trousselard, M. E., Khoury-Malhame, M., Zendjidjian, X., Fakra, E., et al. (2015). Acute stress disorder modifies cerebral activity of amygdala and prefrontal cortex. Cogn. Neurosci. 6, 39-43. doi: 10.1080/ 17588928.2014.996212

Rolls, E. T., Grabenhorst, F., and Parris, B. A. (2008). Warm pleasant feelings in the brain. Neuroimage 41, 1504-1513. doi: 10.1016/j.neuroimage.2008.03.005

Roseman, I. (1984). Cognitive Determinants of Emotion: A Structural Theory. Beverly Hills, CA: Sage.

Russell, J. (2003). Core affect and the psychological construction of emotion. Psychol. Rev. 110, 145-172. doi: 10.1037//0033-295x.110.1.145

Russell, J. A. (2006). Emotions are not modules. Can. J. Philos. Suppl. 32, 53-71. doi: $10.1353 /$ cjp. 2007.0037

Ryff, C. D. (2014). Psychological well-being revisited: advances in the science and practice of eudaimonia. Psychother. Psychosom. 83, 10-28. doi: 10.1159/ 000353263

Ryff, C. D. (2018). Well-being with soul: science in pursuit of human potential. Perspect. Psychol. Sci. 13, 242-248. doi: 10.1177/1745691617699836

Saarimaki, H., Gotsopoulos, A., Jääskeläinen, I. P., Lampinen, J., Vuilleumier, P., Hari, R., et al. (2016). Discrete neural signatures of basic emotions. Cereb. Cortex 26, 2563-2573. doi: 10.1093/cercor/bhv086

Scarantino, A. (2012). Functional specialization does not require a one-to-one mapping between brain regions and emotions. Behav. Brain Sci. 35, 161-162. doi: $10.1017 /$ s0140525x11001749

Scarantino, A. (2015). Basic Emotions, Psychological Construction and the Problem of Variability. New York, NY: Guildofrd press.

Scarantino, A., and Griffiths, P. (2011). Dont give up on basic emotions. Emot. Rev. 3, 444-454. doi: 10.1177/1754073911410745

Schlosberg, H. (1952). The description of facial expressions in terms of two dimensions. J. Exp. Psychol. 44, 229-237. doi: 10.1037/h0055778

Schlosberg, H. (1954). Three dimensions of emotions. Psychol. Rev. 61, 81-88.

Schultz, W., Dayan, P., and Montague, P. R. (1997). A neural substrate of prediction and reward. Science 275, 1593-1599. doi: 10.1126/science.275.5306. 1593

Selvaraj, S., Walker, C., Arnone, D., Cao, B., Faulkner, P., Cowen, P. J., et al. (2018). Effect of citalopram on emotion processing in humans: a combined 5-HT1A [(11)C]CUMI-101 PET and functional MRI study. Neuropsychopharmacology 43, 655-664. doi: 10.1038/npp.2017.166

Sieger, T., Serranová, T., Rùžièka, F., Vostatek, P., Wild, J., Štastná, D., et al. (2015). Distinct populations of neurons respond to emotional valence and arousal in the human subthalamic nucleus. Proc. Natl. Acad. Sci. U.S.A. 112, 3116-3121. doi: $10.1073 /$ pnas. 1410709112

Siep, N., Tonnaer, F., van de Ven, V., Arntz, A., Raine, A., Cima, M., et al. (2018). Anger provocation increases limbic and decreases medial prefrontal cortex connectivity with the left amygdala in reactive aggressive violent offenders. Brain Imaging Behav. .

Song, Y., and Hakoda, Y. (2018). Selective impairment of basic emotion recognition in people with autism: discrimination thresholds for recognition of facial expressions of varying intensities. J. Autism Dev. Disord. 48, 1886-1894. doi: 10.1007/s10803-017-3428-2

Sroufe, L. (1996). Emotional Development. New York, NY: Cambridge University Press.
Takahashi, Y. K., Roesch, M. R., Stalnaker, T. A., Haney, R. Z., Calu, D. J., Taylor, A. R., et al. (2009). The orbitofrontal cortex and ventral tegmental area are necessary for learning from unexpected outcomes. Neuron 62, 269-280. doi: 10.1016/j.neuron.2009.03.005

Taylor, S. F., Ho, S. S., Abagis, T., Angstadt, M., Maixner, D. F., Welsh, R. C., et al. (2018). Changes in brain connectivity during a sham-controlled, transcranial magnetic stimulation trial for depression. J. Affect. Disord. 232, 143-151. doi: 10.1016/j.jad.2018.02.019

Telzer, E. H., Fuligni, A. J., Lieberman, M. D., and Galvan, A. (2014). Neural sensitivity to eudaimonic and hedonic rewards differentially predict adolescent depressive symptoms over time. Proc. Natl. Acad. Sci. U.S.A. 111, 6600-6605. doi: $10.1073 /$ pnas.1323014111

Thayer, R. (1989). The Origion of Everyday Moods: Managing Energy, Tension and Sress. New York, NY: Oxford University Press.

Troy, A. S., Wilhelm, F. H., Shallcross, A. J., and Mauss, I. B. (2010). Seeing the silver lining: cognitive reappraisal ability moderates the relationship between stress and depressive symptoms. Emotion 10, 783-795. doi: 10.1037/a0020262

Trutti, A. C., Mulder, M. J., Hommel, B., and Forstmann, B. U. (2019). Functional neuroanatomical review of the ventral tegmental area. Neuroimage 191, 258-268. doi: 10.1016/j.neuroimage.2019.01.062

Vetter, N. C., Drauschke, M., Thieme, J., and Altgassen, M. (2018). Adolescent basic facial emotion recognition is not influenced by puberty or own-age bias. Front. Psychol. 9:956. doi: 10.3389/fpsyg.2018.00956

Vrticka, P., Lordier, L., Bediou, B., and Sander, D. (2014). Human amygdala response to dynamic facial expressions of positive and negative surprise. Emotion 14, 161-169. doi: 10.1037/a0034619

Wager, T. D., Lindquist, M., and Kaplan, L. (2007). Meta-analysis of functional neuroimaging data: current and future directions. Soc. Cogn. Affect. Neurosci. 2, 150-158. doi: 10.1093/scan/nsm015

Wang, F. (2018). Emotional Psychoogy. Beijing: Health Press.

Wang, F., Pan, F., Shapiro, L. A., and Huang, J. H. (2017). Stress induced neuroplasticity and mental disorders. Neural Plast. 2017:9634501.

Wang, F., Pan, F., Shapiro, L. A., and Huang, J. H. (2018). Stress induced neuroplasticity and mental disorders 2018. Neural Plast. 2018:5382537.

Watson, D., and Clark, L. (1988). Developmental and validation of brief measures of positive and negative affect: the PANAS scale. J. Personal. Soc. Psychol. 54, 1063-1070. doi: 10.1037//0022-3514.54.6.1063

Weierich, M. R., Wright, C. I., Negreira, A., Dickerson, B. C., and Barrett, L. F. (2010). Novelty as a dimension in the affective brain. Neuroimage 49, 2871-2878. doi: 10.1016/j.neuroimage.2009.09.047

Weiskrantz, L. (1956). Behavioral changes associated with ablation of the amygdaloid complex in monkeys. J. Comp. Physiol. Psychol. 49, 381-391. doi: $10.1037 / \mathrm{h} 0088009$

Wicker, B., Keysers, C., Plailly, J., Royet, J. P., Gallese, V., Rizzolatti, G., et al. (2003). Both of us disgusted in My insula: the common neural basis of seeing and feeling disgust. Neuron 40, 655-664. doi: 10.1016/s0896-6273(03)00679-2

Williams, L. E., and Bargh, J. A. (2008). Experiencing physical warmth promotes interpersonal warmth. Science 322, 606-607. doi: 10.1126/science.1162548

Williams, R. (2017). Anger as a basic emotion and its role in personality building and pathological growth: the neuroscientific, developmental and clinical perspectives. Front. Psychol. 8:1950. doi: 10.3389/fpsyg.2017.01950

Wilson-Mendenhall, C. D., Barrett, L. F., and Barsalou, L. W. (2013). Neural evidence that human emotions share core affective properties. Psychol. Sci. 24, 947-956. doi: 10.1177/0956797612464242

Wise, R. A. (2004). Dopamine and food reward: back to the elements. Am. J. Physiol. Regul. Integr. Comp. Physiol. 286, R13.

Wise, R. A. (2006). Role of brain dopamine in food reward and reinforcement. Philos. Trans. R. Soc. Lond. Ser. B Biol. Sci. 361, 1149-1158. doi: 10.1098/rstb. 2006.1854

Wise, R. A. (2008). Dopamine and reward: the anhedonia hypothesis 30 years on. Neurotox Res. 14, 169-183. doi: 10.1007/bf03033808

Wise, R. A. (2013). Dual roles of dopamine in food and drug seeking: the drivereward paradox. Biol. Psychiatry 73, 819-826. doi: 10.1016/j.biopsych.2012.09. 001

Wise, R. A., and Rompre, P. P. (1989). Brain dopamine and reward. Annu. Rev. Psychol. 40, 191-225. doi: 10.1146/annurev.psych.40.1.191

Xu, X., Brown, L., Aron, A., Cao, G., Feng, T., Acevedo, B., et al. (2012). Regional brain activity during early-stage intense romantic love predicted relationship 
outcomes after 40 months: an fMRI assessment. Neurosci. Lett. 526, 33-38. doi: 10.1016/j.neulet.2012.08.004

Yik, M., Russell, J. A., and Steiger, J. H. (2011). A 12-point circumplex structure of core affect. Emotion 11, 705-731. doi: 10.1037/a0023980

Yokel, R. A., and Wise, R. A. (1975). Increased lever pressing for amphetamine after pimozide in rats: implications for a dopamine theory of reward. Science 187, 547-549. doi: 10.1126/science.1114313

Zheng, Z., Simeng, G., Lei, Y., Shanshan, L., Wang, W., Yang, L., et al. (2016). Safety needs mediate stressful events induced mental disorders. Neural Plast. 2016:8058093.
Conflict of Interest Statement: The authors declare that the research was conducted in the absence of any commercial or financial relationships that could be construed as a potential conflict of interest.

Copyright $\odot 2019$ Gu, Wang, Cao, Wu, Tang and Huang. This is an open-access article distributed under the terms of the Creative Commons Attribution License (CC BY). The use, distribution or reproduction in other forums is permitted, provided the original author(s) and the copyright owner(s) are credited and that the original publication in this journal is cited, in accordance with accepted academic practice. No use, distribution or reproduction is permitted which does not comply with these terms. 